\title{
Relative Deprivation, Sexually Transmitted Diseases and HIV and AIDS Mortality: A Multilevel Analysis
}

\author{
Augustine J. Kposowa* \\ Department of Sociology, Watkins Hall, University of California, Riverside, USA \\ *Corresponding author: Augustine.kposowa@ucr.edu \\ Received June 10, 2014; Revised July 12, 2013; Accepted July 16, 2014
}

\begin{abstract}
Objectives: Previous studies on the covariates of sexually transmitted diseases have concentrated on absolute deprivation, often measured by poverty. The aim of this study was to examine the association between relative deprivation (income inequality) and sexually transmitted diseases, and HIV and AIDS mortality. Method: Ecological data based on 3080 counties were obtained from the Area Resource File. State level data on the 50 states and the District of Columbia were derived from the Statistical Abstract of the United States. Multilevel generalized linear models were fitted to the data. Results: State level relative deprivation (measured as the Gini coefficient of income inequality) was strongly and significantly associated with both sexually transmitted diseases ( $b=12.96$, $\mathrm{t}=4.27, \mathrm{p}=.000$ ), and HIV and AIDS mortality ( $\mathrm{b}=20.41, \mathrm{t}=5.58, \mathrm{p}=.000$ ). Absolute deprivation (poverty) was also associated with sexually transmitted diseases, but the association was not as strong as that of relative deprivation. Furthermore, poverty was not significantly associated with HIV and AIDS mortality at the county level. Conclusion: It was concluded that to reduce sexually transmitted diseases and HIV/AIDS, attention should be placed on combating economic inequality and poverty. One tack is to reduce social marginalization of segments of the population.
\end{abstract}

Keywords: HIV and AIDS, sexually transmitted diseases, relative deprivation, poverty, mix models

Cite This Article: Augustine J. Kposowa, "Relative Deprivation, Sexually Transmitted Diseases and HIV and AIDS Mortality: A Multilevel Analysis." American Journal of Infectious Diseases and Microbiology, vol. 2, no. 3 (2014): 55-62. doi: 10.12691/ajidm-2-3-4

\section{Introduction}

Although sexually transmitted diseases are largely preventable, they remain a major social and public health challenge as well as a leading cause of morbidity both nationally and internationally (World Health Organization 2007; 2009). In the United States, there are approximately 19 million new STD cases each year, with almost half of them among persons in the age group 15 to 24 (CDC 2011). The overall incidence rates of the most common sexually transmitted diseases (Chlamydia, gonorrhea, and syphilis) have grown substantially in the past decade. In the entire US population, the rate of STD incidence was 129.4 per 100,000 population in 1996, while in 2008 the rate was 213.4 representing an increase of 64.9 percent (National Center for Health Statistics 2011). It is known that many cases of sexually transmitted diseases go undiagnosed, and some of the most common viral types, such as human papillomavirus (HPV) and genital herpes are not reported to state and Federal agencies. Thus, the reported cases of Chlamydia, gonorrhea, and syphilis make up only a fraction of the true prevalence of all sexually transmitted diseases in the country (CDC 2011). Consequently, the cost of STDs to the U.S. health care system, estimated in 2010 to be as much as $\$ 17.9$ billion annually (CDC 2011) may itself represent an underestimate.
An extensive literature now exists on covariates of sexually transmitted diseases, but some of the findings are inconsistent, especially regarding the role of poverty (Kposowa 2013a; Kposowa 2013b). Different investigators often working with the same set of variables have produced remarkably different results. Some scholars (Reif et al. 2006; Thomas 2006; Farley 2006; Aral et al 2006; Mayer et al. 2008) report that poverty is associated with sexually transmitted diseases. Other analysts have challenged these findings, and failed to find support for poverty (O’Leary et al. 2006; Ellen et al. 1995; Moran et al. 1989). Part of the problem for the discrepancies may stem from the fact that in the conceptualization of poverty, investigators have failed to make distinctions between key concepts: relative deprivation and absolute deprivation. Most of the research on sexually transmitted diseases, especially at the ecological level has relied on absolute deprivation. Thus, our understanding of the contribution of relative deprivation to sexually transmitted diseases is limited.

The purpose of this paper was to examine the impact of relative deprivation on the incidence of sexually transmitted diseases and human immunodeficiency virus deaths. The basic question asked is the following: Does relative deprivation affect rates of STD and AIDS mortality? Is absolute deprivation linked to sexually transmitted diseases? Of the two measures, which has a stronger effect on sexually transmitted diseases and HIV- 
AIDS deaths? What are research and policy implications of the findings with regard to reducing infection and mortality rates?

\subsection{Relative and Absolute Deprivation}

The concept Relative Deprivation first appeared in the work of Stouffer et al. (1949), but the researchers failed to provide a definition. Subsequent rigorous treatment was undertaken by Runciman (1966, p. 10) who described the concept in the following manner:

If $\mathrm{A}$, who does not have something but wants it, compares himself to $\mathrm{B}$, who does have it, then $\mathrm{A}$ is relatively deprived with reference to B. Similarly, if A's expectations are higher than B's or if he was better off than B in the past, he may when similarly placed to B feel relatively deprived by comparison with him.

From the above, an individual's feeling of deprivation stems from making a comparison of his material position in society with that of persons that are better off in the same society. This comparison and the resulting deprivation has the potential to generate societal conflict or tensions (Chakravarty 2009). Relative deprivation then involves making some comparison between what one has (e.g. income) versus what some reference group or person has. The magnitude or intensity of the deprivation depends on the discrepancy between the material situation desired and the individual's perceived situation, which could be past, present, or even future (Stack 1984). According to Runciman (1966) the degree of relative deprivation depends on the intensity with which it is felt. Although some scholars (Webber 2007) have tried to downplay the role of envy, Runciman (1966, p. 14) clearly indicated that relative deprivation entails feelings of envy and injustice stemming from a discrepancy between one's group and a reference group. The group to which a person belongs feels a sense of inequality relative to a comparison group. In US society, for instance, a social group may be aware that others in a different social group have earnings equal to or higher than the average for the community. The greater the disparity the greater the magnitude and intensity of relative deprivation, and the higher the likelihood that felt deprivation might impact health and other outcomes.

Absolute deprivation is based on some fixed standards of living that are judged necessary for basic subsistence (Rosenfeld 2010). In the United States, for example, the Federal government has maintained a minimum subsistence threshold since the early 1960s, and for the most part, it has remained unchanged, except for periodic adjustments for inflation (Kerbo 1996). The absolute deprivation measure utilized by the US government originated from researchers at the Social Security Administration, and it is based on family consumption data going as far back as the mid 1950s (Wilson 1987, 1996). The absolute deprivation measure is based on income thresholds, and individuals or families whose yearly earnings fall below that threshold are declared to be in poverty. Despite a barrage of criticisms from social scientists about the weakness in this approach to quantifying deprivation (Quadagno 1994; Wilson 1987, 1996), the Federal government stubbornly adheres to its conceptualization and measurement of poverty. The absolute deprivation (poverty) approach has been criticized for failing to take into account dramatic changes in family budget allocations, changes in living standards, changes in family structure, and vast regional disparities in costs of living (Rosenfeld 2010; Quadagno 1994).

It should be noted that both relative and absolute deprivation are income/earnings based measures. Absolute deprivation is derived from an income threshold for maintaining a minimum standard of living, but relative deprivation entails income distributions (Messner et al. 2010). The general consensus among critiques of absolute deprivation is that poverty minimizes the true extent of economic inequality in society, and is a poor measure of the gap between the rich and less fortunate members of any community. The present research uses relative deprivation, but for comparison purposes, poverty (absolute deprivation) is also employed. It is hypothesized that relative deprivation has significant effects on both sexually transmitted disease rates and HIV and AIDS mortality.

\section{Methods}

\subsection{Data}

Data were obtained from the 2002 release of the Area Resource File (Bureau of Health Professions 2002). The ARF is a county-level database that combines information from over 75 primary data sources into a single file to facilitate health analysis. The file contains over 6,000 variables for all counties in the United States with the exception of the case of Alaska, for which there is a state total, and certain independent cities that have been combined into their appropriate counties. The 2000 ARF comprises 3,224 records (counties or county equivalents). The ARF is designed to be used by planners, policymakers, researchers, and other analysts interested in the nation's health care delivery system and factors that may impact health status and health care in the United States. The basic county-specific file is the nucleus of the file, although the data can easily be aggregated into larger geographic units (Bureau of Health Professions 2002). This release of the ARF was used because it contained all the variables of interest. Furthermore, theoretically valid social relationships hold across time, and are not eliminated by data age. Counties were selected as the primary unit of analysis for three main reasons: First, they are independent geographic and political entities. Second, they often constitute a critical unit for the formulation of infectious disease, health and social service policies, and third, data on infectious diseases are readily available at the county level (Kposowa 2009). Counties constituted level 1. Secondary data that could not be obtained at the county level were derived from the state. State level data (except where noted) were obtained from the Statistical Abstract of the United States (US Department of Commerce 1993).

\subsection{Dependent Variables}

Two outcome variables were used in the analysis. The first comprised three sexually transmitted diseases (gonorrhea, Chlamydia, and syphilis) occurring in 1990, 1991, and 1992. They were defined using the $9^{\text {th }}$ revision of the International Classification of Diseases (ICD-9Clinical Modification) with the underlying cause codes 
090 through 099 (Practice Management Information [PMIC] 1998). Deaths due to HIV disease were defined using code 042 (PMIC 1998). Cases for HIV and AIDS were completed deaths wherein sexually transmitted diseases were not deaths, but incidents of reporting. It should be noted, of course that not all incidents of HIV and AIDS are sexually related. Mortality from HIV and AIDS was measured as the number of deaths per 100,000 population, 1990 through 1992. To improve reliability of the estimates, rates of gonorrhea, syphilis, and Chlamydia were summed and averaged over the three reporting years (1990 through 1992). The same was done for HIV and AIDS deaths.

\subsection{Independent Variables}

The independent variables were selected based on theoretical relevance as well as findings from past research. To minimize problems arising from endogeneity, as much as possible, independent variables were measured prior to the outcome variable. In addition, care was taken to select measurements based on a census year (e.g. 1990) as opposed to those based on estimates provided in an intercensal period. The main independent variables were relative deprivation, which was measured using the Gini Coefficient of household income inequality (Langer 1999; Kposowa et al. 1995; Lhila \& Simon 2010). The Gini values were obtained from Langer (1999, p. 63) who calculated it using household income. The second variable was absolute deprivation or poverty. It was measured as the percentage of persons below the Federal Government's poverty line in 1990. Percent female headed households has been found strongly correlated with poverty in criminological research (Kposowa et al. 1995) and it is a major component of the disadvantage argument proposed by Wilson $(1987,1996)$. Hence, it was used in place of poverty in some models. The 1990 data were derived from the Statistical Abstract of the United States (US Department of Commerce 1993).

All other variables (including the divorce rate, Southern county, primary care physicians, education, percent urban population, percent without health insurance, and percent church adherents), were used as control variables, employed to minimize the risk of drawing false conclusions. The first was primary care. The definition of primary care in this paper is limited to physicians or doctors of medicine that were in active office-based practice devoted to patient care (National Center for Health Statistics, 1992). The medical areas covered in the NCHS definition of primary care are general practice, general family medicine, general internal medicine, and general pediatrics (NCHS 1992). Physicians in the above specialties that were engaged in teaching or research were excluded. The variable was measured as the number of primary care physicians in a county (meeting the criteria above) per 10,000 population. Another variable was the county divorce rate. It was used as a proxy for availability of expanded sexual networks. It was measured as the percentage females divorced, 1990. The total divorce rate could not be used because it was not available in the Area Resource File.

Other variables used as potential confounders included percent of the state population without health insurance coverage 1990, percent of the population living in urban (metropolitan statistical) areas 1990, state level percent of population that were Church adherents 1990, and Educational attainment, which was measured as percentage of persons aged 25 years and above with less than 9 years of formal schooling in 1990. Regional differences have been reported in both the distribution of poverty and prevalence of sexually transmitted diseases, with the South typically having higher rates of both. The counties were thus divided into South (coded 1) and all others (coded 0 ). Southern counties were those located in the 11 Old Confederacy (Alabama, Mississippi, Georgia, Tennessee, Arkansas, Virginia, Texas, Florida, Louisiana, North Carolina, South Carolina). State level variables (except the Gini coefficient) were obtained from the Statistical Abstract of the United States (US Department of Commerce 1993). Initial analysis showed that percent black population, percent of female headed households and percent in poverty were highly correlated, so those three variables were not included together in models. A list of all variables, along with their means, standard deviations, and minimum and maximum values are shown in Table 1. Due to missing data on the outcome variables, the number of counties in the analysis was 3,080, which represents $95.5 \%$ of all the counties and county equivalents in the country. Data were missing because some counties did not report their STD, HIV and AIDS information to the National Center for Health Statistics. Mean substitution or imputation were ruled out as options for obtaining missing data because the number of counties without data were relatively few ( $n=144$ or $4.5 \%$ of the entire universe of counties).

\subsection{Statistical Estimation}

The response variables in the analysis include the average county STD rate per 1,000 resident population, and HIV deaths per 100,000 resident population. Preliminary analyses entailed determining the distributions of the two outcome variables in order to ascertain the most appropriate estimation technique(s) to use. HIV and AIDs are relatively low base rate events, and although sexually transmitted diseases are less rare, univariate plots showed that both variables were nonnormal. Generalized linear models thus had to be explored. Among the many distributions that exist, coming up with the most appropriate was based on examining descriptive statistics and plots. For STDs, a Poisson or negative binomial distribution approach seemed reasonable, given the highly skewed nature of the variable (skewness=6.697). At the same time, since 286 counties (9.3\%) had no reported STD cases in the three year period of observation, the issue of zero inflation could not be ignored. Statistical tests for zero inflated negative binomial showed that the logit of being an 'extra zero' was -2.284 ( $\mathrm{p}<.0001)$. For HIV and AIDS, tests for zero inflation showed that the logit of being an 'extra zero' was $-0.730(\mathrm{p}<.0001)$. Furthermore, HIV and HIV/AIDS was highly skewed (skewness=15.381), and 1315 US counties (43\%) had no incidents of HIV/AIDS deaths.

In view of the above test outcomes, it was decided that using either the Poisson or Negative Binomial distribution would lead to biased parameter estimates that would result from depressed standard errors. Logistic regression was selected as the alternative for both dependent variables. 
Given that information was collected at both county and state levels hierarchical (bi-level) models were fitted to the data. A multilevel model is a regression model that is used for predicting values of an outcome variable (usually at level 1) using variables at more than one level simultaneously. One hallmark of this approach is that it enables the analyst to examine differences in outcome due to clustering (e.g. counties are nested within states), while simultaneously explaining the dependent variable itself using information at both level 1 (counties) and level 2 (states). Level 2 units (states) are understood as a sample of states drawn from a population of states (Kposowa \& Glyniadaki 2012). A random intercept logit model (Dai, Li, \& Rocke, 2014; Snijders \& Bosker 2004) may be specified as follows:

$$
\begin{gathered}
\operatorname{logit}\left(\pi_{\mathrm{ij}}\right)=\alpha_{\mathrm{j}}+\beta \mathrm{X}_{\mathrm{ij}} \\
\alpha_{\mathrm{j}}=\alpha+\mathrm{u}_{\mathrm{j}}
\end{gathered}
$$

In equation 1 , the effects of states are estimated by the random intercepts $\alpha_{\mathrm{j}}$ (where ${ }_{\mathrm{j}}=1, \ldots \mathrm{J}$ ), a linear combination of a grand mean $(\alpha)$, and a deviation $\left(\mathrm{u}_{\mathrm{j}}\right)$ from that grand mean. $\mathrm{u}_{\mathrm{j}}$ is a random variable that is assumed to be distributed normally uj $\approx N\left(0, \sigma_{u}{ }^{2}\right)$ and independent of random errors at level 1 (counties). State intercepts capture differentials in the logit of sexually transmitted diseases between states, adjusted for other covariates that may be placed in the equation. The first part of the equation (county level) specifies the log odds of sexually transmitted diseases as the sum of an intercept for a county nested in a state along with that county's characteristics. The second part of equation 1 provides state level intercepts as the sum of the grand or overall mean and the random departures from that mean (Snijders \& Bosker 2004; Dai et al. 2014). Equation 1 is multi level, but it is somewhat cumbersome for estimation purposes.
Hence, it is easier to combine both parts into one as shown below:

$$
\operatorname{logit}\left(\pi_{\mathrm{ij}}\right)=\alpha_{\mathrm{j}}+\beta \mathrm{X}_{\mathrm{ij}} \mathrm{u}_{\mathrm{j}}
$$

The fixed effects of the model are depicted by $\alpha$ and $\beta$, and the random effects are represented by $\mathrm{u}_{\mathrm{j}}$. All variables of interest to an analyst may be included at either level, but in the name of brevity, only one variable, $\mathrm{X}$ (at the county level) has been included in equation 2. To aid in the interpretation of the parameter estimates, independent variables at both county and state levels were grand mean centered. Following mean centering, the intercept term $(\alpha)$ reflects the average sexually transmitted disease or HIV and AIDS mortality rate for counties that are coded 0 (non-Southern counties), and the mean value for all other variables. Parameters were estimated using the GLIMMIX procedure in SAS, version 9.3 (SAS Institute 2013).

\section{Results}

\subsection{Descriptive Statistics}

Table 1 presents descriptive statistics on all the variables employed in the analysis. As already noted, both sexually transmitted disease rates and HIV and AIDS deaths were highly skewed. Skewness on STDs was 6.697, and that on HIV and AIDS was 15.381. Due to this violation of the normality assumption, both variables were recoded so that counties with STD rates above 0 were coded 1 , and those with 0 STDs were coded 0 . The same coding scheme was employed for HIV and AIDS. As noted above, the analysis comprised 3080 US counties, nested in 50 states. Descriptive statistics on the variables are shown in Table 1. Variance inflation factors have also

\begin{tabular}{|c|c|c|c|c|c|c|}
\hline Variable & Mean & SD & Skew & Min & Max & VIF \\
\hline Sexually Transmitted Diseases/1000 Population & 17.84 & 13.65 & 6.69 & 0.00 & 5.86 & - \\
\hline HIV and AIDS deaths/100000 population & 4.68 & 9.90 & 15.38 & 0.00 & 5.80 & - \\
\hline State Gini Coefficient of Income Inequality, 1989 & 0.45 & 0.02 & -0.17 & 0.41 & 0.54 & 2.28 \\
\hline Percent Persons below poverty, 1990 & 16.73 & 7.92 & 1.30 & 0.00 & 63.10 & 3.64 \\
\hline Percent Female Headed households, 1990 & 13.24 & 5.29 & 1.40 & 0.00 & 41.10 & 7.93 \\
\hline Southern County (coded 1) & 0.36 & 0.48 & 0.58 & 0.00 & 1.00 & 2.99 \\
\hline Primary Care Physicians/10,000, 1990 & 58.34 & 33.10 & 1.26 & 0.00 & 406 & 1.12 \\
\hline Percent Females Divorced, 1990 & 7.63 & 2.19 & 0.16 & 0.80 & 17.50 & 2.40 \\
\hline Pct persons 25+ with $<9$ Years Schooling, 1990 & 14.54 & 7.28 & 1.05 & 0.60 & 56.30 & 2.41 \\
\hline Percent Urban Population, 1990 & 36.15 & 29.40 & 0.36 & 0.00 & 100 & 1.89 \\
\hline Pct State Pop without health Insurance, 1990-92 & 14.06 & 4.19 & 0.39 & 6.80 & 22.00 & 3.15 \\
\hline Percent Church Adherents, 1990 & 56.45 & 10.22 & -0.50 & 30.50 & 79.60 & 1.400 \\
\hline
\end{tabular}
been provided for the reader's convenience.

Table 1. Descriptive Statistics of Dependent and Independent Variables

Note: VIF=variance inflation factors. These were calculated in a multiple regression equation with sexually transmitted diseases as the dependent variable.

To assess the potential for multicollinearity among independent variables, two tacks were employed. First, Pearson product moment correlations were examined to give an idea of variables that were highly associated at the bivariate level. Secondly, variance inflation factors (VIF) were calculated via Ordinary Least Squares in a multiple regression model with sexually transmitted diseases as the dependent variable. The VIF values were added to Table 1. Given that OLS was not used as estimator in this paper, it was inappropriate to present a separate table on the VIF

analysis. OLS was used just as a tool to assess multicollinear inefficiencies.

Correlational analysis results (not presented) showed a very high association between percent female-headed households and percent black population $(r=0.803$, $\mathrm{p}=.0001)$. Counties with high poverty had higher number of households headed by women $(r=0.516, p=.0001)$, and Southern counties tended to have higher income inequality than northern counties ( $r=0.605, p=.0001)$. Counties with higher female-headed households tended to have higher 
state income inequality as measured by Gini ( $r=0.411$, $\mathrm{p}=.0001$ ). Based on the pattern of inter-relationships among some variables and calculated variance inflation factors, it was decided not to place highly associated variables in the same equation. Thus, while poverty and Gini could enter one equation, female-headed households could not be placed in the same equation as percent in poverty. Its VIF was 7.9. Likewise, percent black population was excluded from all equations due to its high association with poverty $(\mathrm{r}=0.404, \mathrm{p}=.0001)$, femaleheaded households $(\mathrm{r}=0.803, \mathrm{p}=.0001)$, and Southern counties $(\mathrm{r}=0.582, \mathrm{p}=.0001)$. The only variables included in multivariate models simultaneously were those that had variance inflation factors less than 4.0. This cutoff point is below what has been suggested in the econometric literature (Greene, 2003; Kennedy 1998).

\subsection{Multivariate Statistics}

Table 2. Multilevel Logit Analysis of the Effect of Gini and Poverty on Sexually Transmitted Diseases, United States, 1990-1992

\begin{tabular}{|l|l|l|l|}
\hline Covariates & $\beta$ & t-value & Prob. \\
\hline County Level (1) & & & \\
\hline Intercept $(\alpha)$ & $3.052^{* *}$ & 11.18 & 0.001 \\
\hline Percent in poverty, 1990 & -0.003 & -0.21 & 0.833 \\
\hline Divorce rate, 1990 & $0.308^{* *}$ & 6.29 & 0.001 \\
\hline County in the South, 1990 (coded 1) & $1.954^{* *}$ & 3.27 & 0.001 \\
\hline Primary Care Physicians per 10,000, 1990 & 0.000 & 0.48 & 0.630 \\
\hline Pct persons 25+ with $<9$ Years Schooling, 1990 & 0.032 & 1.85 & 0.064 \\
\hline Percent Urban Population 1990 & $0.043^{* *}$ & 10.34 & 0.001 \\
\hline State Level (2) & & & 0.001 \\
\hline Percent without health Insurance, 1990 & $-0.201^{* *}$ & -3.29 & 0.805 \\
\hline Percent Church Adherents, 1990 & 0.004 & 0.25 & 0.019 \\
\hline Gini coefficient of Income inequality, 1990 & $30.500^{* *}$ & 2.33 & \\
\hline Variance Components & & & \\
\hline Intercept $\left(\sigma_{u}^{2}\right)($ State) & $0.929^{* *}$ & 3.01 & \\
\hline Generalized Chi-Square & 2462.64 & & \\
\hline Gener. Chi-Squre/DF & 0.80 & & \\
\hline Number of Events (STD=1) & 2794 & & \\
\hline Number of Counties & 3080 & & \\
\hline Number of States & 50 & & \\
\hline Maximum Counties per State & 254 & & \\
\hline
\end{tabular}

**Significant at $\mathrm{p}<.01 ; \beta=$ unstandardized logistic coefficient.

The county divorce rate elevated the log odds of county sexually transmitted diseases $(\beta=0.309, \mathrm{t}=6.29, \mathrm{p}=.0001)$. The unstandardized logistic regression coefficient $(\beta)$ means that for every percent increase in the percentage divorced, the log of the odds of sexually transmitted diseases in the county increased by nearly 0.31 . The rate of primary care physicians in a county had no association with rates of sexually transmitted diseases. Percentage of persons with less than 9 years of education was not significantly associated with county STD rates. Urban counties were associated with much higher odds of STD rates $(\beta=0.043, \mathrm{t}=10.34, \mathrm{p}=.0001)$.

The higher the percentage of the population without health insurance the lower the log of the odds of STDs. For instance for every percent increase in the percentage without health insurance, the county STD rate declined by 0.201 on average on the logit scale $(\beta=-0.201, t=-3.29$, $\mathrm{p}=.001$ ). Given that health insurance is likely to facilitate routine hospital visits, lack of insurance might delay physician contacts, and thus delay possible diagnosis and
Relevant results of the effect of absolute deprivation (poverty) and relative deprivation (Gini) on sexually transmitted diseases are shown in Table 2. First, it can be seen that the estimated variance of the state intercepts was 0.929 with a corresponding standard error of 0.305 $(\mathrm{t}=3.04)$. The parameter measures differences among states, and its significance $(\mathrm{t}=3.04)$ is an indication that there is a state effect on the log odds of sexually transmitted diseases.

It may also be observed in the table that a unit increase in the measure of income inequality (Gini) at the state level increased the county STD rate by nearly 30.5 points on the logit scale $(\beta=30.5, \mathrm{t}=2.33, \mathrm{p}=.009)$. Poverty was not significantly associated with sexually transmitted diseases. On average, Southern counties had higher odds of sexually transmitted diseases than those outside the South $(\beta=1.95, \mathrm{t}=3.27, \mathrm{p}=.001)$. mandatory reporting of a sexually transmitted disease. State Church membership rate was not associated significantly with the county STD rate. When femaleheaded households was placed in the equation as a substitute for poverty (findings not shown), it was significantly associated with sexually transmitted diseases $(\beta=0.163, t=4.59, p=.0001)$. Results with regard to other variables did not change.

Summary of the results of the analysis of the association between income inequality and HIV-AIDs mortality are shown in Table 3 . The covariance parameter estimate was 1.498, with a standard error of 0.4119 $(t=3.64)$. This indicated a significant state effect on HIV and AIDS mortality.

Relative deprivation or income inequality (as measured by the Gini coefficient) was significantly linked to deaths from HIV and AIDS. For each additional increase in the Gini coefficient at the state level, the county death rate from AIDS increased by 54.23 on the logit scale $(\beta=54.23$, $\mathrm{t}=4.00, \mathrm{p}=.0001)$. Absolute deprivation, indexed by 
poverty was not significantly associated with the odds of

county HIV and AIDS mortality.

Table 3. Multilevel Logit Analysis of the Effect of Gini and Poverty on HIV and AIDS Mortality, United States, 1990-1992

\begin{tabular}{|l|l|l|l|}
\hline Covariates & $\beta$ & t-value & Prob. \\
\hline County Level (1) & & & \\
\hline Intercept $(\alpha)$ & 0.064 & 0.23 & 0.820 \\
\hline Percent in poverty, 1990 & -0.014 & -1.33 & 0.184 \\
\hline Divorce rate, 1990 & $0.253^{* *}$ & 7.15 & 0.001 \\
\hline County in the South, 1990 (coded 1) & $1.955^{* *}$ & 3.22 & 0.001 \\
\hline Primary Care Physicians per 10,000, 1990 & -0.000 & -0.56 & 0.057 \\
\hline Pct persons 25+ with $<9$ Years Schooling, 1990 & $-0.057 * *$ & -4.41 & 0.001 \\
\hline Percent Urban Population 1990 & $0.040^{* *}$ & 16.14 & 0.001 \\
\hline State Level (2) & & & \\
\hline Gini coefficient of Income inequality, 1990 & $54.230^{* *}$ & 4.00 & 0.001 \\
\hline Percent without health Insurance, 1990 & $-0.187 * *$ & -2.83 & 0.004 \\
\hline Percent Church Adherents, 1990 & -0.030 & -1.74 & 0.081 \\
\hline Variance Components & & & \\
\hline Intercept $\left(\sigma_{u}^{2}\right)($ State) & $1.498^{* *}$ & 3.636 & \\
\hline Generalized Chi-Square & 2655.3 & & \\
\hline Gener. Chi-Squre/DF & 0.86 & & \\
\hline Number of Events (HIV and AIDS=1) & 1765 & & \\
\hline Number of Counties & 3080 & & \\
\hline Number of States & 50 & & \\
\hline Maximum Counties per State & 254 & & \\
\hline$* *$ Sigifict & \\
\hline
\end{tabular}

$* *$ Significant at $\mathrm{p}<.01 ; \beta=$ unstandardized logistic coefficient.

The divorce rate was associated significantly with HIV and AIDS deaths $(\beta=0.253, \mathrm{t}=7.14, \mathrm{p}=.0001)$, and counties in the South had significantly higher odds of mortality from AIDS than counties outside the South $(\beta=1.955$, $\mathrm{t}=3.22, \mathrm{p}=.001)$. Availability of primary care physicians had no effect on death from HIV and AIDS, but percent urban population $(\beta=0.040, \mathrm{t}=16.14, \mathrm{p}=.0001)$ elevated the odds of death. Low education, measured by percent of the population 25 years old with less than 9 years of schooling reduced the log of the odds of death from HIV and AIDS $(\beta=-0.057, t=-4.41, p=.0001)$.

States with a higher percentage lacking health insurance had reduced rates of mortality from HIV and AIDS (on the logit scale) at the county level $(\beta=-0.187, t=-2.83, p=.004)$. Percent church adherents in the state had no influence on the odds of mortality from HIV and AIDS. Finally the variable percent female-headed household was substituted for poverty in the HIV and AIDS equation. Results (not provided) showed that it was a highly significant determinant of mortality $(\beta=0.047, \mathrm{t}=11.65, \mathrm{p}=.0001)$ from HIV and AIDS.

\section{Discussion}

The aim of the paper was to investigate the impact of relative deprivation (income inequality) on the incidence of sexually transmitted diseases and HIV/AIDS mortality. Earlier studies employing relative deprivation as an explanatory concept were in the field of Sociology, where it was observed that the greater the relative deprivation, the higher the crime rates (Chester 1976; Stack 1984; Kennedy et al. 1998; Messner et al. 2010). Some sociological work showed that while relative deprivation was associated significantly with property crime rates, it was not significantly related to personal violent crimes (Kposowa et al. 1995; Stack 1984).

Application of the concept in the literature on sexually transmitted diseases is rare (Lhila \& Simon 2010). Holtgrave \& Crosby (2012) found income inequality correlated with HIV/AIDS case rates in 48 American states, but results for other STDs were not statistically significant. Moreover, the authors relied too heavily on correlational analysis without adequate controls for potential confounders.

A question could be asked: why and how could relative deprivation or income inequality lead to higher rates of sexually transmitted diseases and HIV and AIDS? One possibility is that the association observed is not a direct, but an indirect link. As has been noted in the sociology, high levels of inequities in material assets may create resentment which then leads to a state of disequilibrium or disruptions in social cohesion, and a general decline in community and individual quality of life (Merton 1938; Messner \& Rosenfeld 1994; Kawachi et al. 1999). Pronounced income inequalities generate a sense of lavish wealth that is in view, but at the same time, not within reach of vast segments of society (Kawachi et al. 1999). Possible consequences include individual and community resentment, alienation, discontent, depression, anxiety, and a sense of injustice (Blau \& Blau 1982). Thus, visible economic inequalities might create frustration and stress that leads to reduced inhibition, greater use of alcohol and illicit drugs, unsafe sexual habits, which ultimately elevate higher chances of transmitting or getting infected with a sexually transmitted disease. Some scholars (Aral et al. 2006) have speculated that poor economic conditions might create psychological depression, which elevates risky sexual behavior. High levels of economic inequality might also contribute to the creation and maintenance of drug markets, wherein some who aspire to the 'American Dream' but find their paths blocked resort to crime (Merton 1938), including the sale and distribution of drugs. Participation in drug markets has been pointed out in the 
literature as a risk factor for sexually transmitted diseases (Thomas 2006; Thomas \& Thomas 1999; Rogers et al. 2012). Income inequality may also be tied to health insurance. It is plausible that the deprived lack jobs that enable maintenance of health insurance that enables not only having quality care, but continuing care. This is especially probable in the United States where there is no universal healthcare, and being jobless in essence means living without insurance and being unable to visit hospitals except in an emergency.

Relative deprivation was consistently and significantly associated with both sexually transmitted diseases and HIV and AIDS mortality. This finding is at variance with that of Holtgrave \& Crosby (2012) which reported that income inequality predicted rates of HIV and AIDS, but not rates of gonorrhea, syphilis or Chlamydia. A plausible reason for the discrepant findings is that while their investigation used only 48 states, the present research has used nearly the entire universe of counties in the United States, leading to greater statistical power. It is also possible that use of multilevel analysis in the present research has accounted for clustering, which was not considered in the Holtgrave \& Crosby (2012) study.

Findings on income equality held even after taking into account other variables, including the measure of absolute deprivation (poverty). Results show evidence to suggest that to fight STDS and HIV/AIDS public policy should not ignore societal inequities. For example, lack of health insurance reduced STD rates, a finding that suggests that persons inflicted with an STD, but lacking insurance might not visit health care providers, and may thus not be diagnosed soon.

While income inequality may not be a proximate cause of STDs, it may be a distal contributor because it creates the social environment (e.g. sexual networks) in which behavioral and proximate biological factors are more likely to be affected. As Kposowa (2013b) observed, for nearly every cause of mortality or nearly every type of morbidity, the most socially disadvantaged and marginalized are overrepresented.

A significant difference was observed between Southern and non-Southern counties with regard to sexually transmitted disease and HIV/AIDS mortality rates. It is plausible that part of the difference is the regional variations in poverty and inequality to which some past studies have alluded (Reif et al. 2006; Butler et al. 2000). Religious conservatism in the South (Kposowa 2013a) could also be suspect in the higher incidence of sexually transmitted disease and HIV/AIDS in that region. Where there is religious conservatism, there may be a greater tendency to avoid discussions of sex in the home, and sex education in schools may be inadequate or even absent; sexual abstinence may be stressed, and for some, especially the young, abstinence may not work. Thus, failure of abstinence, coupled with misinformation about sexually transmitted diseases could combine to elevate higher rates in the South. Although the present study controlled partially for religion through church membership, a strong Southern effect still remained for both STDs and HIV and AIDS. Given that poverty was also in the equations, there may be other unique attributes of the South that make the region have higher rates of STDS and HIV and AIDS deaths.
There are limitations to the study which the reader is warned to bear in mind. First, analyses have been done at the ecological level (counties and states). Therefore, it is inappropriate to generalize conclusions to individual Americans, as that might raise the risk of committing the ecological fallacy noted by Robinson (1950). Second, sexually transmitted diseases are underreported in the United States due to the fact that in some segments of the population, having these infections is still considered a source of shame and embarrassment (Moran et al. 1989; Thomas et al. 2009). This study has, thus relied on only reported cases or incidents of three STDs; their true prevalence in the population is unknown, and may well have been underestimated in the analysis.

Despite the above and other limitations, findings reported in the present study are important for health demography and sociological science. The main message in this research from the point of view of public policy is that to combat sexually transmitted diseases and HIV and AIDS, attention should be placed on combating economic inequality. One tack is to reduce marginalization of segments of the population, as failure to do so could have deleterious consequences. A marginalized and disenfranchised group tends to be low in social capital and collective efficacy (Coleman 1990; Putnam 1993; 1995), lack voice in local, state and even Federal political debates, and thus be ignored by policy makers. For instance, aggressive efforts by conservative legislators in some states to pass laws requiring voters to show specific forms of identification before being allowed to cast votes in future elections in the United States show how easy it is for the economically deprived and less fortunate members of society to be silenced by elites. Given that those without economic power often lack the specified identification documents (e.g. driving licenses, birth certificates, and passports), voter id laws effectively disenfranchise them permanently, reducing them to second class citizens. A key feature of a democracy is the ability of citizens to recall their leaders. This is typically done through periodic elections in which people vote. If subsections of the population are denied the right to vote and in the process completely ignored, it is unlikely that important health issues pertaining to them will ever find their way into public policy debates. This is one reason why both relative deprivation (income inequality) and absolute deprivation (poverty) remain important variables to consider when dealing with population health.

\section{References}

[1] Adamora, A., \& Schoenbach, V.J. (2006). HIV and African Americans in the southern United States: sexual networks and social context. Sexually Transmitted Diseases, 33, 000-000.

[2] Banks, J., Marmot, M., Oldfield, Z., Smith, J.P. (2006). Disease and disadvantage in The United States and in England. JAMA, 295, 2037-2045.

[3] Becker, K.M., Glass, G.E., Brathwaite, W., \& Zenilman, J.M. (1998). Geographic Epidemiology of gonorrhea in Baltimore, Maryland using a geographic information system. American Journal of Epidemiology, 147, 709-716.

[4] Blau, P.M., \& Blau, J.R. (1982). The cost of inequality: metropolitan structure and violent crime American Sociological Review, 47, 114-129.

[5] Braun, D. (1997). The Rich Get Richer: The Rise of Income Inequality in the United States and the World. Chicago: NelsonHall Publishers. 
[6] Bureau of Health Professions. (2002). Area Resource File [machine readable data file] Washington, DC: Data Distributor.

[7] Butler, C. (2000). HIV and AIDS, poverty, and causation Lancet, 356, 1445-1446.

[8] Centers for Disease Control and Prevention (2011) Sexually transmitted disease Surveillance 2010. Atlanta, GA. Accessed at www.cdc.gov/std/stats 10 January 2013 9:45:38 PM

[9] Chakravarty, S.R. (2009). Deprivation, inequality and welfare Japanese Economic Review, 60, 172-190

[10] Chester, C.R. (1976). Perceived relative deprivation as a cause of property crime Crime \& Delinquency, 22, 17-30

[11] Coleman, J.S., (1990). The Foundations of Social Theory Cambridge, MA: Harvard University Press.

[12] Dai, J., Li, Zhongmin, \& Rocke, D. (2014) Hierarchical Logistic Regression Modeling with SAS GLIMMIX. Accessed online 23 February 2014 at http://www.lexjansen.com/wuss/2006/analytics/ANL-Dai.pdf.

[13] Greene, W. H. (2003). Econometric Analysis Upper Saddle River, NJ: Prentice Hall.

[14] Hallfors, D.D., Iritani, B.J., Miller, W.C., \& Bauer, D.J. (2007). Sexual and drug behavior patterns and HIV and STD racial disparities: the need for new directions. American Journal of Public Health, 97, 125-132.

[15] Hogben, M., \& Leichliter, J.S. (2008). Social determinants and sexually transmitted disease disparities. Sexually Transmitted Diseases, (supplement), 35, S13-S18.

[16] Holtgrave, D.R. \& Crosby, R.A. (2012). Social capital, poverty, and income inequality as predictors of gonorrhea, syphilis, Chlamydia and AIDS case rates in the United States Sexually Transmitted Infections, 79, 62-64.

[17] Kawachi, I., Kennedy, B.P., \& Wilkinson, R.G. (1999). Crime: social disorganization and relative deprivation Social Science \& Medicine, 48, 719-731.

[18] Kennedy, B.P., Kawachi, I., Prothrow-Stith, D., Lochner, K., \& Gupta, V. (1998) Social capital, income inequality, and firearm violent crime Social Science \& Medicine, 47, 7-17.

[19] Kennedy, P. (1998) A Guide to Econometrics Cambridge, MA: MIT Press.

[20] Kerbo, H.R. (1996). Social Stratification and Inequality: Class Conflict in Historical and Comparative Perspective. New York: The McGraw-Hill Companies, Inc.

[21] Kposowa, A.J. (2013a). Poverty, HIV, and sexually transmitted diseases. Pp. 89-104 in Poverty and Health: a Crisis among America's Vulnerable. Edited by Kevin M. Fitzpatrick. Santa Barbara, CA: Praeger.

[22] Kposowa, A.J. (2013b) Marital status and HIV-AIDS mortality: evidence from the US National Longitudinal Mortality Study, International Journal of Infectious Diseases, 17, e868-e874.

[23] Kposowa, A.J., \& Glyniadaki, A. (2012). Mental health and suicide: an ecological hierarchical analysis of U.S Counties and States. Pp. 289-308 in Opportunities and Challenges for Applied Demography in the $21^{\text {st }}$ Century, edited by Nazrul Hoque and David A. Swanson. New York: Springer.

[24] Kposowa, A.J. (2009). Psychiatrist availability, social disintegration and suicide deaths in U.S. Counties, 1990-1995. Journal of Community Psychology, 37, 73-87.

[25] Kposowa, A.J., Breault, K.D., \& Harrison, B. (1995). Reassessing the structural covariates of violent and property crimes in the United States: a county level analysis, British Journal of Sociology, 46, 79-105.

[26] Langer, L. (1999). Measuring income distribution across space and time in the American states. Social Science Quarterly, 80, 5567.

[27] Lhila, A., \& Simon, K.I. (2010). Relative deprivation and child health in the USA Social Science \& Medicine, 71, 777-785.

[28] Mayer, K., Pizer, H.F., \& Venkatesh, K.K. (2008). The social ecology of HIV/AIDS. Medical Clinics of North America, 92, 1363-1375.

[29] Merton, R.K. (1938). Social structure and anomie American Sociological Review, 3,672-682.

[30] Messner, S.F., \& Rosenfeld, R. (1994). Crime and the American Dream Belmont, CA: Wadsworth Publishing Company.

[31] Messner, S.F., Raffalovich, L.E., \& Sutton, G.M. (2010). Poverty, infant mortality, and homicide rates in cross-national perspective: an assessment of criterion and construct validity Criminology, 48, 509-537.

[32] Moran, J.S., Aral, S.O., Jenkins, W.C., Peterman, T.A., \& Alexander, E.R. (1989). The impact of sexually transmitted diseases on minority populations Public Health Reports, 104, 560565.

[33] National Center for Health Statistics. (1992). Health status indicators: Definitions and national data. Statistical Notes, 1, 1-8.

[34] National Center for Health Statistics (2011). Health, United States, 2010: With Special Feature on Death and Dying. Hyattsville, MD.

[35] O’Leary, A. Broadwell, S.D., Yao, P., Hasin, D. (2006). Major depression, alcohol and drug use disorders do not account for the STD and HIV epidemics in the southern United States Sexually Transmitted Diseases, 33 (Supplement), S70-S77.

[36] Practice Management Information (1998). ICD.9.CM International Classification of Diseases $9^{\text {th }}$ Revision Clinical Modification (fifth edition). Los Angeles: Practice Management Information, Inc.

[37] Putnam, R.D. (1993). Making Democracy Work: Civic Traditions in Modern Italy Princeton, NJ: Princeton University Press.

[38] Putnam, R.D. (1995). Bowling alone: America's declining social capital Journal of Democracy 6, 65-78.

[39] Quadagno, J. (1994). The color of welfare: how racism undermined the war on poverty. New York: Oxford University Press.

[40] Reif, S., Geonnoti,K.L., \& Whetten,K. (2006). HIV and AIDS in the Deep South. American Journal of Public Health, 96, 970-973.

[41] Robinson, W.S. (1950) Ecological correlations and the behavior of individuals American Sociological Review, 15(3): 351-357.

[42] Rolfs, R.T., Goldberg, M., \& Sharrar, R.G. (1990). Risk factors for syphilis: cocaine use and prostitution. American Journal of Public Health, 80, 853-857.

[43] Rogers, S.M., Khan, M.R., Tan, S., Turner, C.F., Miller, W.C., \& Erbelding, E. (2012). Incarceration, high-risk sexual partnerships and sexually transmitted infections in an urban population Sexually Transmitted Infections, 88, 63-68.

[44] Rosenfeld, J. (2010). The meaning of poverty and contemporary quantitative poverty research British Journal of Sociology, 61, 103-110.

[45] Runciman, W.G. (1966). Relative deprivation and social justice London: Routledge Kegan Pau.

[46] SAS Institute (2013) SAS Stats: The GLIMMIX Procedure version 9.3 [computer software]. Cary, NC: SAS Institute, Inc.

[47] Stack, S. (1984). Income inequality and property crime Criminology, 22, 229-256.

[48] Stouffer, S.A., Lumsdaine, M.H., Williams, M.B., Smith, I.L. (1949). The American Soldier: adjustment during army life (vols 1-2). Princeton, NJ: Princeton University Press.

[49] Thomas, J.C. (2006). From slavery to incarceration: social forces affecting the epidemiology of sexually transmitted diseases in the rural south. Sexually Transmitted Diseases, 33 (supplement), S6S10.

[50] Thomas, J.C., Kulik, A.L., \& Schoenbach, V.J. (1995). Syphilis in the south: rural rates surpass urban rates in North Carolina. American Journal of Public Health, 85, 1119-1122.

[51] Thomas, J.C. \& Thomas, K.K. (1999). Things ain't what they ought to be: social forces underlying racial disparities in rates of sexually transmitted diseases in a rural North Carolina county Social Science \& Medicine, 49,1075-1084.

[52] Thomas, J.C., Torrone, E.A., \& Browning, C.R. (2009). Neighborhood factors affecting rates of sexually transmitted diseases in Chicago Journal of Urban Health, 87, 102-112.

[53] US Department of Commerce.(1993). Statistical Abstract of the United States Washington, DC: Author.

[54] Webber, C. (2007). Revaluating relative deprivation theory Theoretical Criminology, 11, 97-120.

[55] Wilson, W.J. (1987). The Truly Disadvantaged Chicago: University of Chicago Press.

[56] Wilson, W.J. (1996). When work disappears New York: Random House.

[57] World Health Organization (2007). Addressing Sex and Gender in Epidemic-Prone Infectious Diseases. Geneva: WHO.

[58] World Health Organization (2009). Women and Health: Today's Evidence Tomorrow's Agenda. Geneva: WHO. 